\title{
Photodegradation of fluoroquinolones in aqueous solution under light conditions relevant to surface waters, toxicity assessment of photoproduct mixtures.
}

\section{Sarka Klementova ( $\sim$ sklement@jcu.cz)}

University of South Bohemia Faculty of Science: Jihoceska Univerzita v Ceskych Budejovicich Prirodovedecka Fakulta https://orcid.org/0000-0003-3646-5945

\section{Martina Poncarová}

University of South Bohemia: Jihoceska Univerzita v Ceskych Budejovicich

\section{Helena Langhansová}

University of South Bohemia Faculty of Science: Jihoceska Univerzita v Ceskych Budejovicich Prirodovedecka Fakulta

\section{Jaroslava Lieskovská}

University of South Bohemia Faculty of Science: Jihoceska Univerzita v Ceskych Budejovicich

Prirodovedecka Fakulta

\section{David Kahoun}

University of South Bohemia Faculty of Science: Jihoceska Univerzita v Ceskych Budejovicich Prirodovedecka Fakulta

\section{Pavla Fojtíková}

University of South Bohemia Faculty of Science: Jihoceska Univerzita v Ceskych Budejovicich Prirodovedecka Fakulta

\section{Research Article}

Keywords: iprofloxacin, enrofloxacin, norfloxacin, photodegradation, antibacterial activity of photoproducts

Posted Date: April 20th, 2021

DOI: https://doi.org/10.21203/rs.3.rs-274285/v1

License: (c) (i) This work is licensed under a Creative Commons Attribution 4.0 International License. Read Full License 
Version of Record: A version of this preprint was published at Environmental Science and Pollution Research on October 2nd, 2021. See the published version at https://doi.org/10.1007/s11356-021-161826. 


\section{Abstract}

Photochemical degradation of fluoroquinolones ciprofloxacin, enrofloxacin and norfloxacin in aqueous solution under light conditions relevant to surface waters at neutral and alkaline $\mathrm{pH}$ was found to proceed readily with half-lives between 0.9 and $2.7 \mathrm{~min}$. The products of photochemical degradation identified by HPLC-MS included defluorinated, hydroxylated, and decarboxylated structures as well as structures with opened cyclic structures. For all of the studied substances, the reaction pathways were influenced significantly by the $\mathrm{pH}$ of the reaction system, with more products formed at alkaline $\mathrm{pH}$ than at neutral $\mathrm{pH}$ : the ratios of products in neutral and alkaline $\mathrm{pH}$ were $16 / 26,9 / 19,15 / 23$ for ciprofloxacin, enrofloxacin, and norfloxacin, respectively. The structures of photoproducts and pathways of photochemical degradation are proposed. The antibacterial activities of photoproduct mixtures tested on E. coli and S. epidermidis were significantly higher in comparison to parental antibiotics in the case of both ciprofloxacin and enrofloxacin with p-values less than 0.0001 in most cases. The effect of the photoproducts was shown to be dependent on the $\mathrm{pH}$ value of the original antibiotic solutions before photodegradation: for ciprofloxacin, antibacterial activity against E. coli was more notably pronounced with regard to neutral $\mathrm{pH}$ photoproducts, while a less significant, or in one case not significant, effect of $\mathrm{pH}$ was observed against S. epidermidis ; for norfloxacin, antibacterial activity against both E. coli and S. epidermidis were especially high with regard to alkaline $\mathrm{pH}$ photoproducts

\section{Introduction}

Antibiotics have been increasingly detected in surface waters in the past few decades, and are thus classified as pollutants of emerging significance, though there is limited understanding of their environmental fate and toxicological effects (Van Doorslaer et al., 2014).

Among antibiotics, fluoroquinolones represent a group widely used in both human and veterinary medicine. According to WHO, fluoroquinolones are considered "highest priority critically important antibiotics" (Roth et al., 2019). An estimation of quinolone production and usage from the year 2007 shows an amount of around 50 tons in the form of proprietary products and 70 tons in the form of generic quinolones for the USA, EU, Japan and South Korea, while with respect to China the estimate reached almost 2000 tons (Sukul \& Spiteller; 2007). The review article of Frade et al. (2014) provides an overview of environmental concentrations of fluoroquinolones found in surface waters, waste water treatment plants influents and effluents and hospital effluents in European countries, the USA, Japan and China - the concentration range is from tens of $\mathrm{ng} / \mathrm{l}$ to several $\mathrm{mg} / \mathrm{l}$ for surface waters as well as for waste-water treatment plant influents. The higest concentrations, reaching hundreds of $\mathrm{mg} / \mathrm{I}$ were found in hospital effluents.

Antibiotics generally exhibit no or extremely low biodegradability (Kümmerer et al., 2000; Vasconcelos et al., 2009). Therefore, photochemical degradation is considered a possibly significant pathway of fluoroquinolone environmental fate (Vasconcelos et al. (2009), Li et al. (2011), Sturini et al. (2012), Sturini 
et al. (2015), Zhichao Zhang et al. (2019). The residual antibiotic activity and possible toxic effects of photoproducts have been reported (Sturini et al. (2012), Sturini et al. (2015)

For toxicity assessments, microorganisms belonging to biosafety level 1 are extremely useful and widely adopted. Escherichia coli and Staphylococcus epidermidis belong to the category of fluoroquinolonesusceptible control strains (Baudry-Simner et al., 2012; Yamada et al., 2008) and are widely used worldwide in studies of antibacterial activity (e.g. Jacobs et al., 2004; Rizzo et al., 2013; Sanhueza et al., 2017) as well as of new approaches to antibiotics applications (Kratochvíl et al. 2018 a); Kratochvíl et al., 2018 b).

The objectives of this study were: (1) To test whether three widely used fluoroquinolone representants, namely ciprofloxacin, enrofloxacin, and norfloxacin, may undergo photochemical degradation under irradiation relevant to natural short-wavelength conditions and at neutral and mildly alkaline $\mathrm{pH}$ values common in natural waters. (2) To reveal whether the degradation pathways and products formed during degradation processes depend on $\mathrm{pH}$. (3) To ascertain whether this degradation leads to complete or partial loss of antibacterial activity.

\section{Materials And Methods}

\section{Photodegradation procedure}

Sample preparation: Ciprofloxacin, enrofloxacin, and norfloxacin (Sigma-Aldrich, all $\geq 98 \%$, HPLC) solutions were prepared by the dissolution of $5 \mathrm{mg}$ of the compound in $4 \mathrm{ml} \mathrm{HCl}(0.1 \mathrm{~mol} / \mathrm{l})$, then diluted to $100 \mathrm{ml}$ with Milli-Q ${ }^{\circledR}$ water. The $\mathrm{pH}$ values were adjusted by $10 \% \mathrm{NaOH}$, for neutral $\mathrm{pH}$ to a range of 7.0 -7.13 , for alkaline $\mathrm{pH}$ to $8.13-8.8$.

Irradiation: Samples containing $3 \mathrm{ml}$ of an antibiotic solution in 1-cm glass cuvettes with PTFE lids were irradiated in a Rayonet reactor with RPR $3000 \AA$ lamps emitting light at a wavelength range of 254$350 \mathrm{~nm}$ - light below $300 \mathrm{~nm}$ was filtered out by optical glass to imitate short-wavelength solar radiation that reaches the Earth's surface. Radiant flux was measured using a Lutron UV A light metre, the total power of all the electromagnetic radiation within the wavelength range $320-390 \mathrm{~nm}$ (the range detected by the Lutron metre) emitted per unit time was calculated for the irradiated area, the value being $4.5 \mathrm{~W}$.

Analyses of samples: The extent of fluoroquinolones photodegradation was determined by HPLC (ThermoScientific Dionex Ultimate, column Phenomenex Kinetex ${ }^{\circledR} 5$ mm EVO C18, $30 \times 2.1$ mm, mobile phase $0.1 \% \mathrm{HCOOH}$ in water and acetonitrile 1:1) with PDA 3000RS spectrophotometric and FLD 3000RS fluorescence detectors. The identification of products was performed using a HPLC-MS system (Thermo Scientific Ultimate 3000 Rapid Separation Quaternary System coupled with Velos Pro mass spectrometer with dual-pressure linear ion trap). The details of HPLC-MS measurement are summarized in Tab. 1. Ion chromatography (Dionex ISC 3000, Dionex Ion Pack AS11-HC column 250 mm, mobile phase $\mathrm{KOH}$ from EG C III KOH eluent generator with AERS 500 suppressor) was applied for the detection of low-molecular charged products. 
Antibacterial activity tests: Escherichia coli Seattle 1946 (ATCC 25922) and Staphylococcus epidermidis RP62A (ATCC 35984) bacterial strains were grown in LB medium overnight at $37^{\circ} \mathrm{C}$ with constant agitation. Then the bacteria were diluted to 200000 cells per $\mathrm{ml}$ of DMEM culture medium supplemented with $10 \%$ fetal calf serum and seeded into 96 -well plate. Undiluted, 10 -fold diluted and 100 -fold diluted samples were added to the bacteria and cultivated at $37{ }^{\circ} \mathrm{C}$ and $5 \% \mathrm{CO}_{2}$ for 3 hours. Bacterial viability was quantified by measuring fluorescence upon excitation and emission wavelengths of $550 \mathrm{~nm}$ and 590 $\mathrm{nm}$, respectively, after an additional 3 and 6 hours of cultivation using alamarBlue ${ }^{\mathrm{TM}}$ Cell Viability Reagent (ThermoFisher Scientific). The values from photoproduct-containing samples were normalized to control (antibiotics without photoproducts), i.e. the metabolic activity of the control samples (as a function of bacterial proliferation) is set to $100 \%$. Data are represented as means and standard error of mean (SEM). Differences between samples were evaluated using 2-way analysis of variance followed by Tukey posthoc test.

\section{Results}

The photoinitiated degradation of the three studied substances (ciprofloxacin, enrofloxacin and norfloxacin) followed first order kinetics. Their kinetic characteristics are summarized in Tab.2. The values of rate constants are of the same order of magnitude, nevertheless ciprofloxacin differed from the other two compounds since it has a higher reaction rate at neutral $\mathrm{pH}$ while enrofloxacin and norfloxacin were degraded more quickly at alkaline $\mathrm{pH}$. The half-lives of the fluoroquinolones under the experimental conditions were in the range of 0.9 to $2.7 \mathrm{~min}$.

The HPLC analyses revealed the formation of a significant amount of intermediates and final products in all reaction systems. Thus, reaction mixtures at irradiation times providing the most complex reaction mixtures were chosen for HPLC-MS and for antibacterial activity tests.

The reaction schemes of ciprofloxacin in neutral and alkaline solution are demonstrated in Fig. 1 and 2, respectively, The observed $\mathrm{m} / \mathrm{z}$ values of products and their proposed structures are summarised in Tab. 3 for neutral $\mathrm{pH}$ and in Tab. 4 for alkaline pH. Tab. 4 contains additional three low-molecular ions (fluoride, formate and acetate) that were detected in the reaction mixture using ion chromatography. The scheme for neutral pH (Fig. 1) contains the pathways for formation of 13 products, The main degradation mechanisms are defluorination, hydroxylation, decarboxylation, and the opening and further degradation of cyclic structures. In alkaline $\mathrm{pH}, 26$ products were documented, for 22 of them their chemical structure has been proposed. Under these conditions, the double hydroxylated product 1 and protonated structure of product 23 are the main sources for a series of further product formation.

The photoinitiated degradation of the three studied substances (ciprofloxacin, enrofloxacin and norfloxacin) followed first order kinetics. Their kinetic characteristics are summarized in Tab.2. The values of rate constants are of the same order of magnitude, nevertheless ciprofloxacin differed from the other two compounds since it has a higher reaction rate at neutral $\mathrm{pH}$ while enrofloxacin and norfloxacin 
were degraded more quickly at alkaline $\mathrm{pH}$. The half-lives of the fluoroquinolones under the experimental conditions were in the range of 0.9 to $2.7 \mathrm{~min}$.

The HPLC analyses revealed the formation of a significant amount of intermediates and final products in all reaction systems. Thus, reaction mixtures at irradiation times providing the most complex reaction mixtures were chosen for HPLC-MS and for antibacterial activity tests.

The reaction schemes of ciprofloxacin in neutral and alkaline solution are demonstrated in Fig. 1 and 2, respectively, The observed $\mathrm{m} / \mathrm{z}$ values of products and their proposed structures are summarised in Tab. 3 for neutral $\mathrm{pH}$ and in Tab. 4 for alkaline pH. Tab. 4 contains additional three low-molecular ions (fluoride, formate and acetate) that were detected in the reaction mixture using ion chromatography. The scheme for neutral pH (Fig. 1) contains the pathways for formation of 13 products, The main degradation mechanisms are defluorination, hydroxylation, decarboxylation, and the opening and further degradation of cyclic structures. In alkaline $\mathrm{pH}, 26$ products were documented, for 22 of them their chemical structure has been proposed. Under these conditions, the double hydroxylated product 1 and protonated structure of product 23 are the main sources for a series of further product formation.

Enrofloxacin at neutral pH (Fig. 3) has the lowest number of products - only nine were found in the reaction mixture, their structures are shown in Tab. 5. In alkaline medium, 19 products were detectable, for 16 of them structures are proposed (Tab. 6). The degradation pathways are presented in Fig. 4.

Fig. 5 and Tab. 7 demonstrate the photochemical degradation of norfloxacin at neutral pH. In this case, 15 products were detected and their structures proposed. Irradiation at alkaline $\mathrm{pH}$ led to 23 products (Fig. 6), for 19 of them proposed structures are presented (Tab. 8).

In all cases, the degradation in alkaline medium lead to a significantly greater amount of products, nevertheless the degradation pathway (defluorination, hydroxylation, decarboxylation, and the opening and further degradation of cyclic structures) were common under all conditions tested.

Antibacterial ativity was tested with paternal compounds and mixtures of photoproducts, i.e. irradiated samples with developed intermediates and products profiles, using the same irradiation times as in the HPLC-MS analyses. Results are summarised in Fig. 7.

As can be seen from Fig. 7, the inhibitory activities against the two tested bacteria strains were significantly higher for photoproducts of ciprofloxacin and enrofloxacin in comparison to the parental antibiotics (numbers in the presence of the respective parental antibiotic represents control column in Fig. 7). Ciprofloxacin photoproducts exhibited higher inhibition towards $E$. coli when irradiated at neutral $\mathrm{pH}$, the effect being more pronounced with increasing cultivation time; a lesser significant inhibitory effect was observed in the reaction mixture of ciprofloxacin irradiated at alkaline $\mathrm{pH}$. The inhibitory effects towards $S$. epidermidis were on the other hand evidently higher in photoproduct mixtures irradiated at mildly alkaline $\mathrm{pH}$. 
Enrofloxacin photoproducts exhibit an extremely significant decrease in the numbers of bacteria towards both tested species with the effect being more noticeable with regard to photoproducts that were formed by photochemical degradation at mildly alkaline $\mathrm{pH}$.

Regarding norfloxacin, no differences in the antibacterial activity of photoproduct mixture when compared to norfloxacin itself were discerned towards either tested species.

\section{Discussion}

The phototranformation of the studied substrates followed first-order kinetics, the values of reaction rate constants are similar to those attained by Babić et al. (2013) and Wammer et al. (2013) for ciprofloxacin and enrofloxacin. They observed a faster photodegradation of norfloxacin, but this may have been caused by a higher concentration of antibiotics in this study in comparison to their experiment, since Babić et al. (2013) noticed a decrease in reaction rate in relation to increasing concentration.

The degradation mechanism of the studied fluoroquinolone antibiotics depends strongly on the $\mathrm{pH}$ value of the irradiated reaction mixture. Even though the main degradation pathways involve in all cases processes such as defluorination, hydroxylation, decarboxylation, and the opening and further degradation of the cyclic structures under all conditions tested, the number of products was noticeably higher when the photodegradation was carried out at alkaline $\mathrm{pH}$. The findings are in agreement with the results of Zhichao Zhang et al. (2019) who revealed the influence of chemical speciation on photochemical transformation of three fluoroquinolones (lomefloxacin, norfloxacin and ofloxacin). In their study, they also observed defluorination, decarboxylation and direct piperazinyl ring oxidation. Generally it can be concluded that at alkaline $\mathrm{pH}$, hydroxylation prevails due to abundant hydroxyl groups. Nevertheless, the hydroxylated products depend on the character of the antibiotics: with ciprofloxacin and norfloxacin, a substitution of the $\mathrm{OH}$ group for the $\mathrm{F}$ atom and a direct hydroxylation of the piperazinyl ring and its futher oxidation and breakage were observed, whereas in enrofloxacin the $\mathrm{OH}$ group was bound to the ethyl group on the piperazinyl group. Enrofloxacin photodegradation provided ciprofloxacin in both neutral and alkaline $\mathrm{pH}$; the production of ciprofloxacin from enrofloxacin was mentioned in the study of Babić et al. (2013), though their subsequent products differ from the products presented in this study, since their reaction mixture contained humic acid which may affect degradation pathways. The products No 7 and $8(\mathrm{~m} / \mathrm{z}=374$ and 358 , respectively) of enrofloxacin photodegradation at neutral pH were noticed by Wammer et al. (2013). Two of the products of enrofloxacin degraded at alkaline pH were reported by Li et al.(2011), product No $2(\mathrm{~m} / \mathrm{s}=316.2 \mathrm{in}+\mathrm{ESI})$ and product No 6 (m/s $=372.2$ in + ESI). Product No $13(\mathrm{~m} / \mathrm{s}=294.1)$ was found by Ahmad et al. $(2015)$.

Antibacterial activity tests performed in the study against two bacterial strains came from the assumption (null hypothesis) that photochemical degradation would result in a decrease or complete loss of antibacterial activity. The loss of antibacterial activity was shown to be true for norfloxacin since the mixture of norfloxacin photoproducts exhibited the same inhibitory effect as the antibiotic itself; since the dose of photoproducts mixture for the test was calculated to contain the same amount of parental 
antibiotics as the antibiotic sample, the result shows conclusively that norfloxacin photoproducts do not contribute to inhibition of the bacterial growth in either tested species. This corresponds with the results of bioluminescent inhibition tests on Vibrio fischeri performed by Zhichao Zhang et al. (2019) in which they observed a significant decrease in toxicity for norfloxacin and ofloxacin.

The null hypothesis about the decrease of antibacterial activity through photochemical degradation must be rejected for the two remaining compounds tested in this study, ciprofloxacin and enrofloxacin. Taking into account the statistical evaluation presented in Fig. 7, only for the pair ciprofloxacin/alkaline photoproducts tested on $E$. coli were the p-values less than or equal to 0.05 and 0.01 for 6 and 9 hour incubation, resp; nevertheless even these values of $p$-value are considered to be significant for rejecting null hypothesis. In all other cases, the pairs control/photoproducts $p$-values were 0.0001 , which means there is an extreme statistical significance that photoproduct toxicity to bacteria is notably higher than those of parent antibiotics themselves. The difference between photoproducts formed at neutral and mildly alkaline $\mathrm{pH}$ and the extremely significant higher toxicity of photoproducts formed in alkaline solution were proven with regard to enrofloxacin toward both tested species. With regard to ciprofloxacin, photoproducts formed at neutral $\mathrm{pH}$ exhibited extremely significant higher antibacterial activity against $E$. coli; against $S$. epidermidis, though no significant difference was observed after longer incubation time. This is in agreement with the results of Sturini et al. (2012) who found that the irradiation of four fluoroquinolone antibiotics (ciprofloxacin, danofloxacin, levofloxacin and moxifloxacin) dissolved in untreated river water under solar light led to photoproducts that possessed residual antibacterial activity towards $E$. coli and S. aureus. The authors attributed the activity manifestation to the products conserving the fundamentals of the fluoroquinolone structure. Since a significant portion of photoproducts detected in our study retain the basic fluoroquinolone structure, the hypothesis that this structure is responsible for the antibacterial activity may be considered viable. Nevertheless, the increased antibacterial effect in some photoproduct mixtures observed in this study suggests that some modifications of the base structure lead to augmentation of the antibacterial effect when compared to the original antibiotic. Thus, though photodegradation may represent a feasible degradation pathway for fluoroquinolone antibiotics in surface waters, there is even the possibility of production substances possessing enhanced antibacterial activity which may pose a threat to microorganism populations.

\section{Declarations}

\section{Acknowledgement}

The authors gratefully acknowledge the financial support of the research provided by the Faculty of Science, University of South Bohemia. Partial financial support was received from the Grant Agency of the Czech Academy of Science - grant number 31-19-15678S. Sincere thanks go to Christopher Steer for his diligent proof-reading of this paper.

Ethical approval and consent to participate: Not applicable 
Consent for publication: Not applicable.

Availability of data and materials: All relevant data generated and analysed during this study are included in the article.

Competing interests: The authors declare that they have no competing interests.

\section{Authors contributions}

Š. Klementová organised and supervised the research and was a major contributor in writing the manuscript.

M. Poncarová performed photochemical experiments and analysed LC-MS data.

H. Langhansová and J. Lieskovská carried out the testing of antibacterial activity.

D. Kahoun supervised the LC-MS measurements.

P. Fojtíková participated in the HPLC analyses.

\section{Funding}

Partial financial support was received from the Grant Agency of the Czech Academy of Science, grant number 31-19-15678S.

\section{References}

Ahmad I, Bano R, Musharraf SG, Sheraz MA, Ahmed S, Tahir H, ul Arfeen Q, Bhatti MS, Shad Z, Hussain SF (2015): Photodegradation of norfloxacin in aqueous and organic solvents: A kinetic study. J. Photochem. Photobiol. A: Chemistry 302:1-10.

Babić S, Periša M, Škorić I (2013): Photomytic degradation of norfloxacin, enrofloxacin and ciprofloxacin in various aqueous media. Chemosphere 91:1635-1642

Baudry-Simner P J, Singh A, Karlowsky JA, Hoban DJ, Zhanel GG (2012): Mechanism of reduced susceptibility to ciprofloxacin in Escherichia coli isolates from Canadian hospitals. Can. J. Infect. Dis. Med. Microbiol. 23 (3):e60-e64.

Frade VMF, Dias M, Costa Teixeira AC, Alves Palma MS (2014): Environmental contamination by fluoroquinolones. Braz. J. Pharm. Sci. 50 (unpaginated).

Jacobs MR, Bajaksouzian S, Windau A, Appelbaum PC, Patel MV, Gupte SV, Bhagwat S, De Souza NJ, Khoradiwala HF (2004): In Vitro Activity of the New Quinolone WCK 771 against Staphylococci.Antimicrob. Agents Chemother. 48:3338-3342. 
Kratochvíl J, Štěrba J, Lieskovská J, Langhansová H, Kuzminova A, Khalakhan I, Kylián O, Straňák V (2018 a).: Atibacterial effect of Cu/C:F nanocomposites deposited on PEEK substrates.Material Letters 230:96-99.

Kratochvíl J, Kahoun D, Štěrba J, Langhansová H, Lieskovská J, Fojtíková P, Hanuš J, Kousal J, Kylián O, Straňák V (2018 b): Plasma pomerized C:H:N:O thin films for controlled release of antibiotic substtances.Plasma Processes and polymers 15: 1700160.

Kümmerer K, Al-Ahmad A, Mersch-Sundermann V (2000): Biodegradability of some antibiotics, elimination of the genotoxicity and affection of wastewater bacteria in a simple test. Chemosphere 40:701-710.

Li Y, Niu J, Wenlong W (2011): Photolysis of Enrofloxacin in aqueous systems under simulated sunlight irradiation: Kinetics, mechanism and toxicity of photolysis products. Chemosphere 85:892-897.

Rizzo L, Fiorentino A, Anselmo A (2013): Advanced treatment of urban wastewater by UV radiation: Effect on antibiotics and antibiotic-resistant E. coli strains.Chemosphere 92:171-176.

Roth N, Käsebohrer A, Mayrhofer S, Zitz U, Hofacre C, Domig K (2019): The application of antibiotics in broiler production and the resulting antibiotic resistance in Escherichia coli: A global overview. Poultry Science 98:1791-1804.

Sanhueza L, Melo R, Montero R, Maisey K, Mendoza L, Wilkens M (2017): Synergistic interactions between phenolic compounds identified in grape pomace extract with natibioticx of different classes against Staphylococcus aureus and Escherichia coli. PloS One 12(2): e0172273.

Sturini M, Speltini A, Maraschi F, Pretali L, Profumo A, Fasani E, Albini A, Migigliavacca R, Nucleo E (2012): Photodegradation of fluoroquinolones in surface water and antimicrobial activity of the photopruducts. Water Res. 46:5575-5582.

Sturini M, Speltini A, Maraschi F, Pretali L, Ferri EN, Profumo A (2015): Sunlight-induced degradation of fluoroquinolones in wastewater effluent: Photoproducts identification and toxicity.Chemosphere 134:313318.

Sukul P, Spiteller M (2007): Fluoroquinolones antibiotics in the environment. Rev. Environ. Contam. Toxicol. 191:131-154.

Van Doorslaer X, Dewulf J, Van Langenhove H, Demeestere K (2014): Fluoroquinolone antibiotics: An emerging class of environmental micropollutants.Sci. Total Environ. 500-501C:250-269.

Vasconcelos T G, Henriques D M, König A, Martins A F, Kümerer K (2009): Photo-degradation of the antimicrobial ciprofloxacin at high $\mathrm{pH}$ : Identification and biodegradability assessment of the primary byproducts. Chemosphere 76:487-493. 
Wammer KH, Korte AR, Lundeen RA, Sundberg JE, McNeill K, Arnold WA (2013): Direct photochemistry of three fluoroquinolone antibacterials: Norfloxacin, ofloxacin and enrofloxacin. Water Res. 47:439-448.

Yamada M, Yoshida J, Hatou S, Yoshida T, Minegawa Y (2008): Mutations in the quinolone resistence determining region in Staphylococcus epidermidis recovered from conjunctiva and their assiciation with susceptibility to various fluoroquinolones.J. Ophthalmol. 92:848-851.

Zhichao Zhang, Xiande Xie, Zhiqiang Yu, Hefa Cheng (2019): Influence of chemical speciation on phtochemical transformation of three fluoroquinolones (FQs) in water: Kinetics, mechanism, and toxicity of photolysis products. Water Res. 148:19-29.

\section{Tables}

Due to technical limitations the tables are available as a download in the Supplementary Files.

\section{Figures}




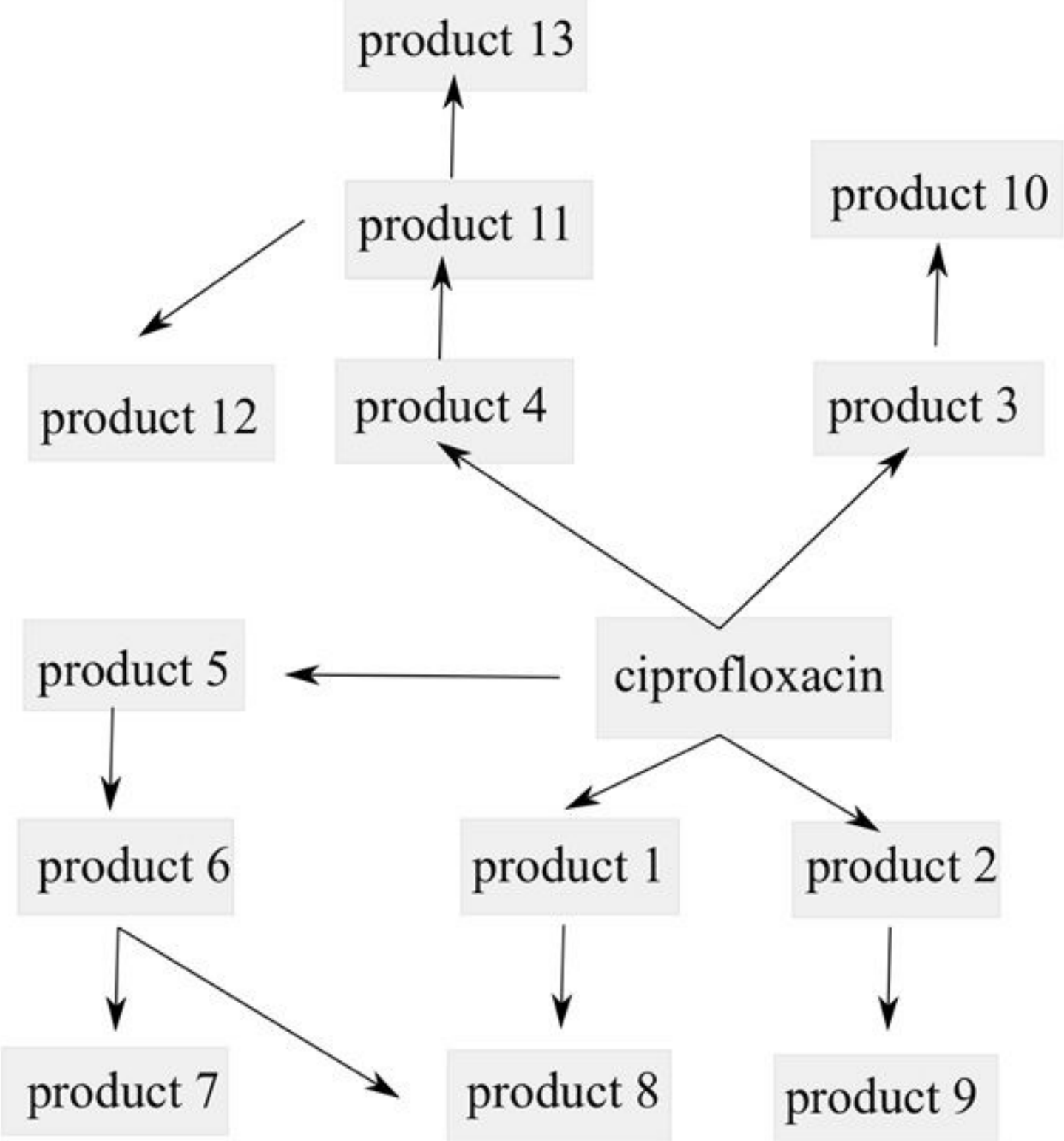

Figure 1

Photodegradation pathways of ciprofloxacin at neutral $\mathrm{pH}(\mathrm{pH}=7.0)$ 


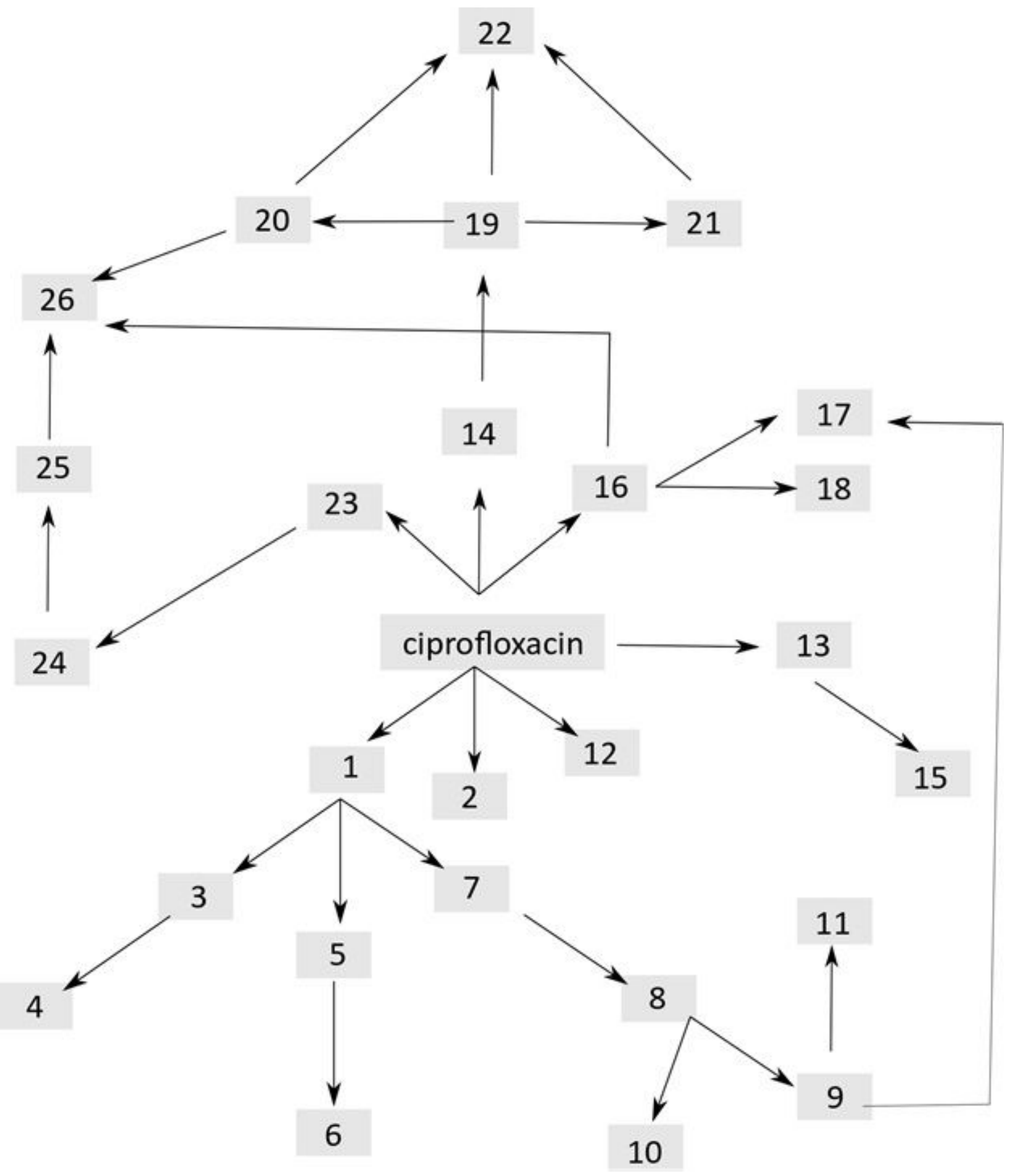

Figure 2

Photodegradation pathways of ciprofloxacin at alkaline $\mathrm{pH}(\mathrm{pH}=8.5)$. Numbers represent individual degradation products according to Tab. 4. 


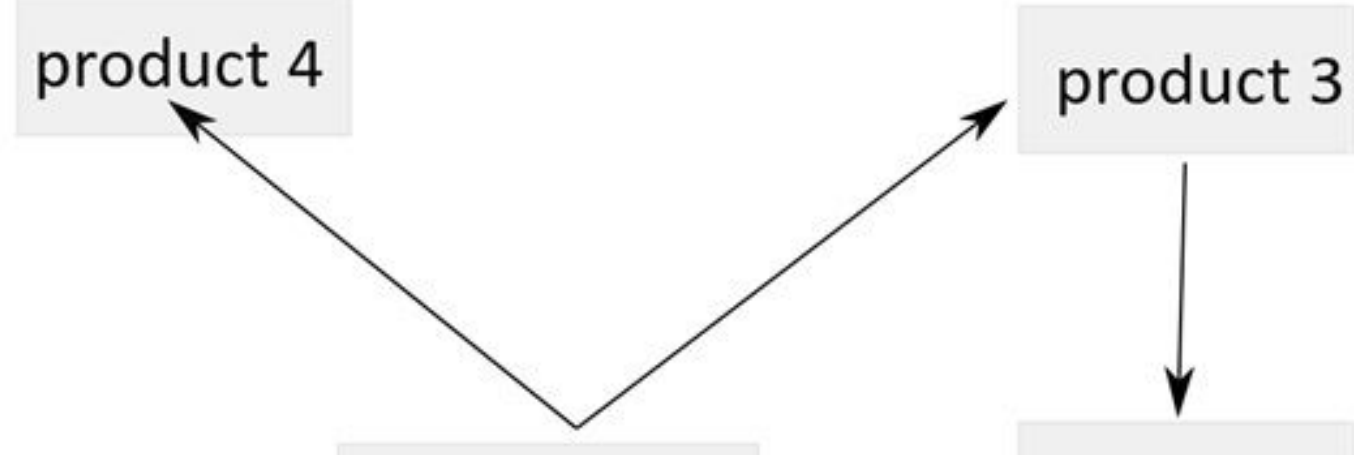

\section{enrofloxacin}

\section{product 7}
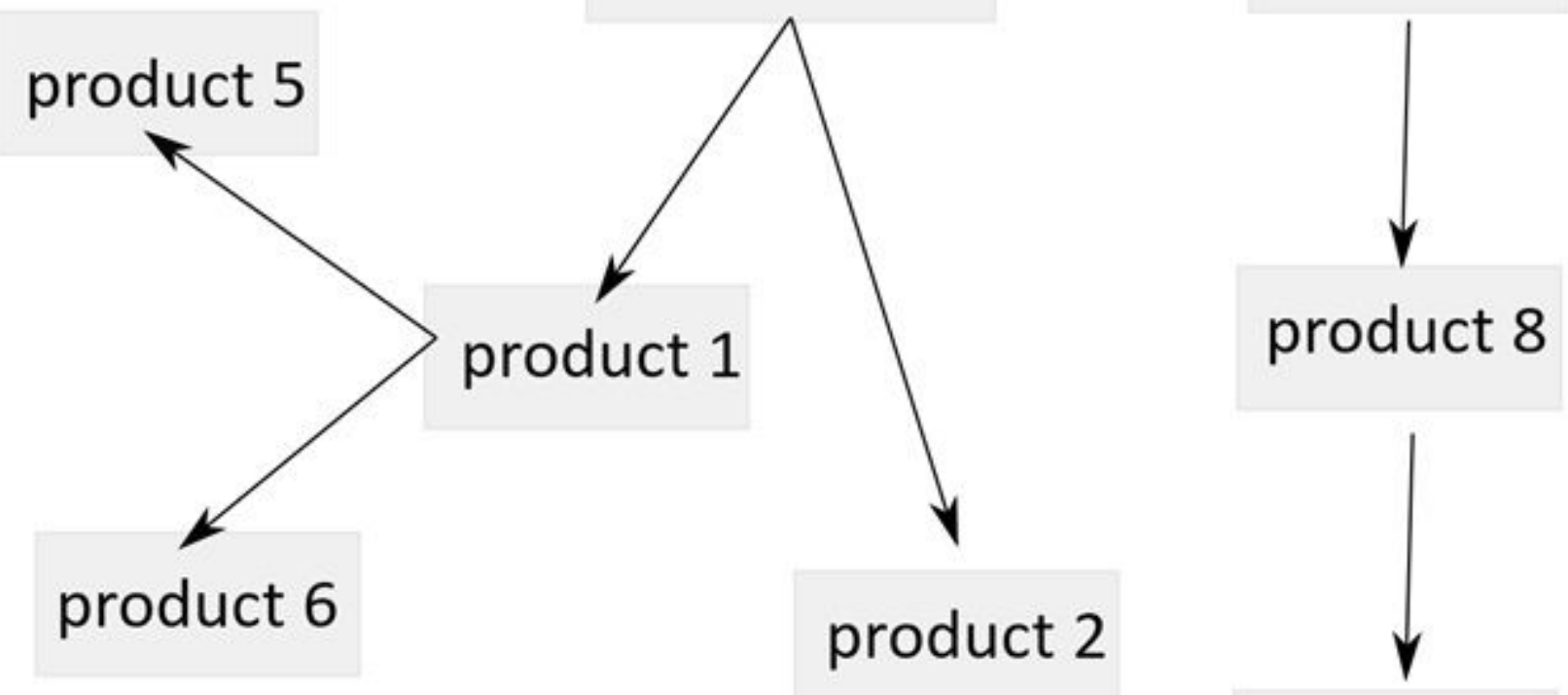

product 9

Figure 3

Photodegradation pathways of enrofloxacin at neutral $\mathrm{pH}(\mathrm{pH}=6.9)$ 


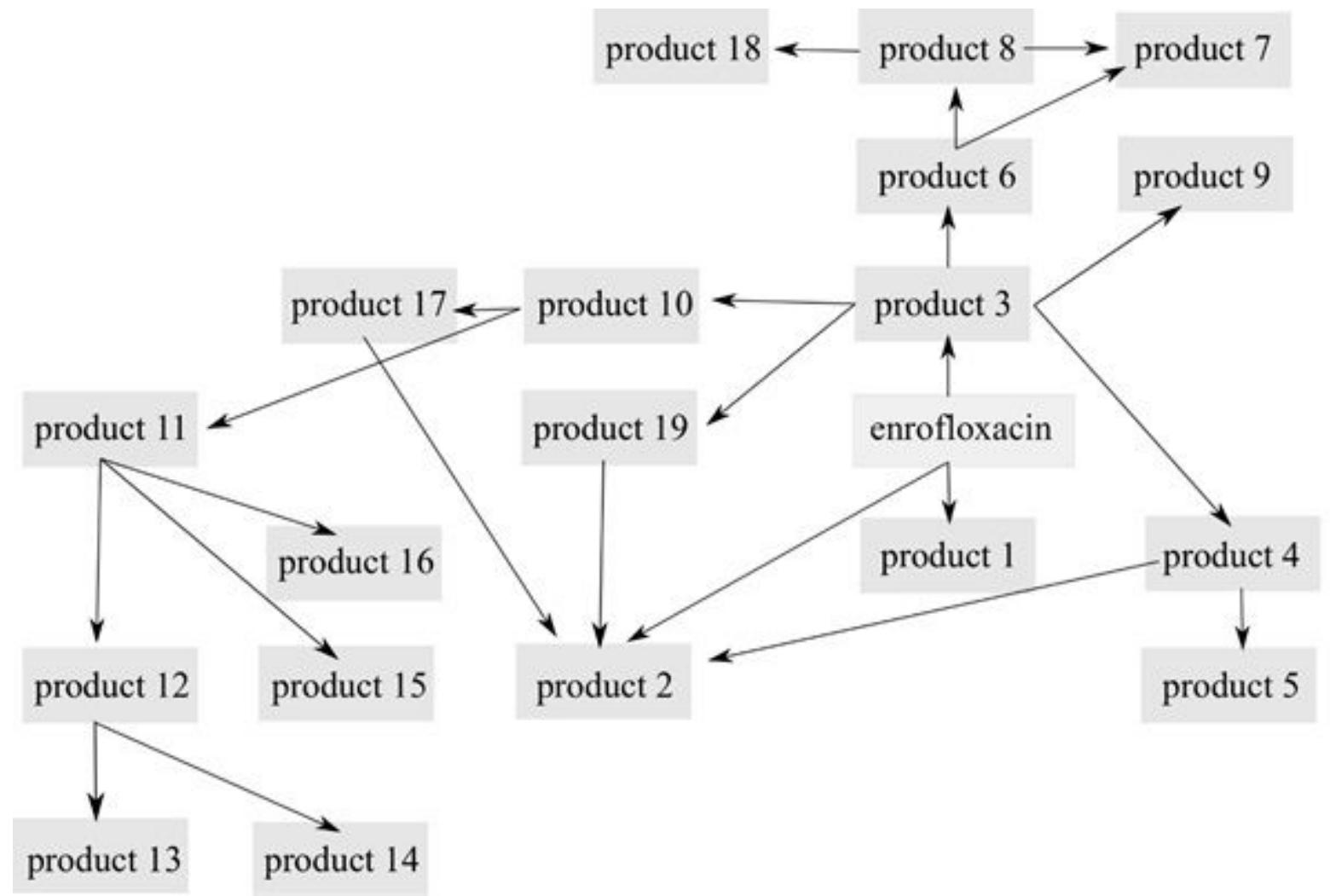

Figure 4

Photodegradation pathways of enrofloxacin at alkaline $\mathrm{pH}(\mathrm{pH}=8.1)$

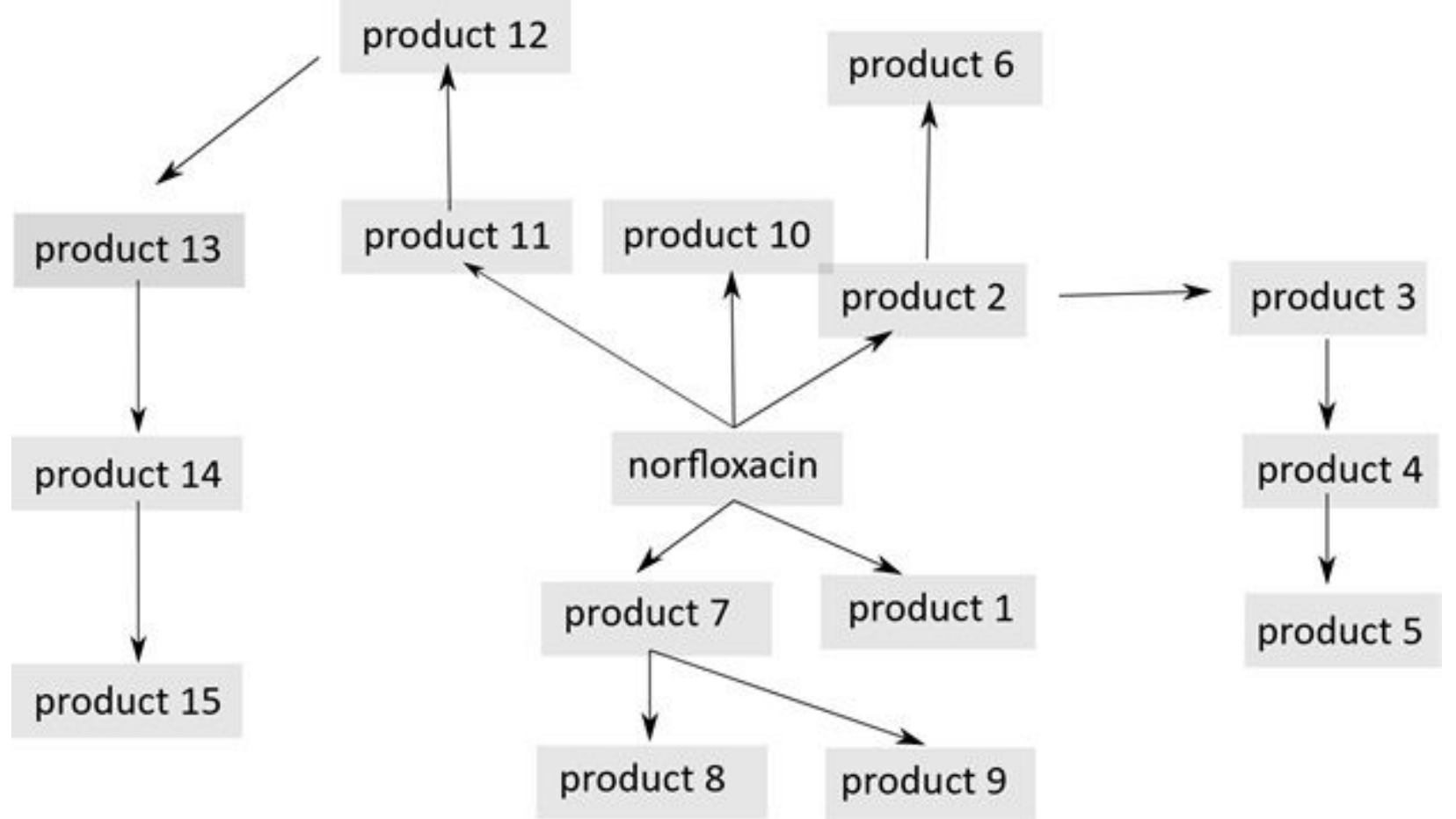

Figure 5

Photodegradation pathways of norfloxacin at neutral $\mathrm{pH}(\mathrm{pH}=7.1)$ 


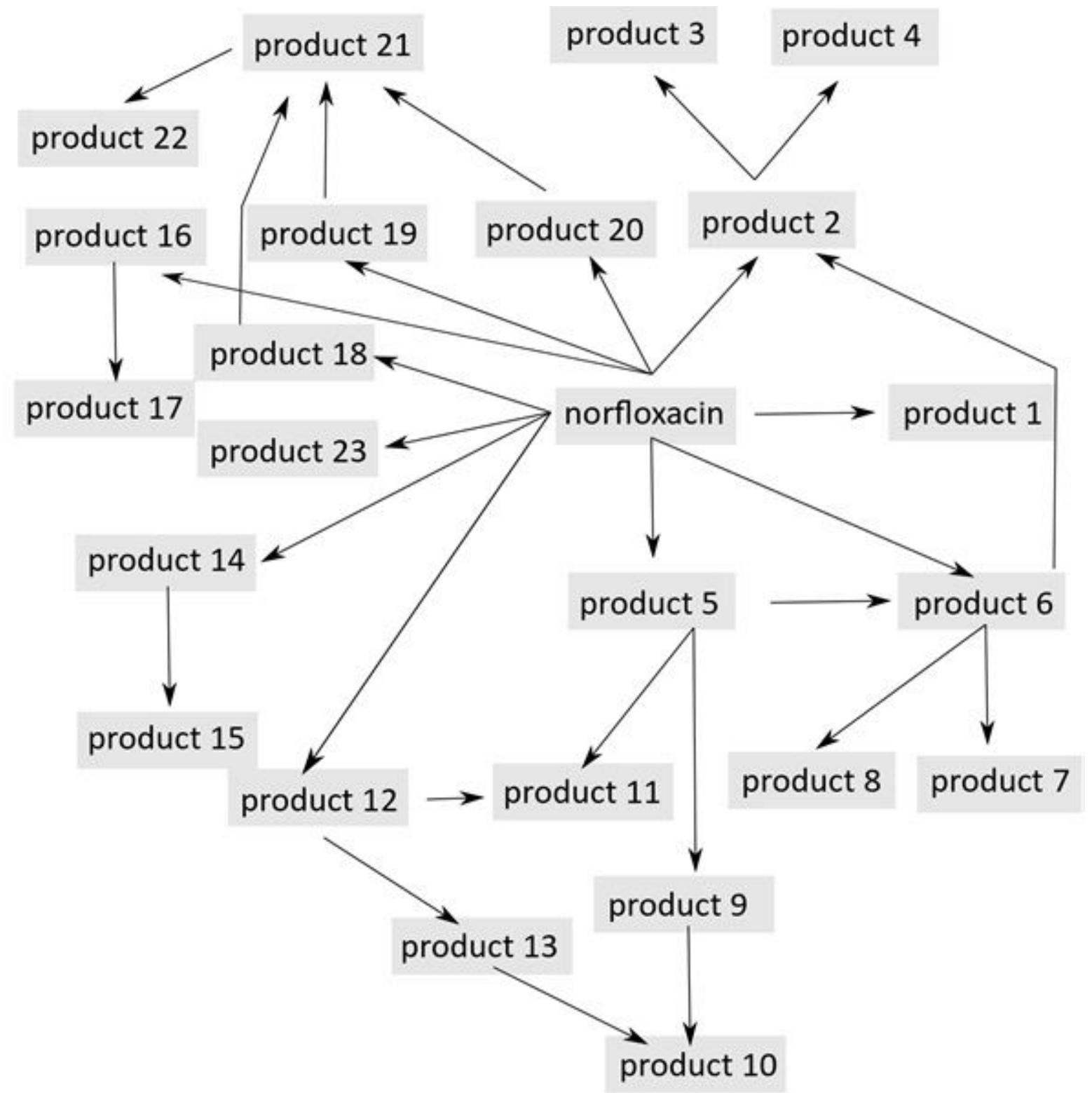

Figure 6

Photodegradation pathways of norfloxacin at alkaline $\mathrm{pH}(\mathrm{pH}=8.9)$ 

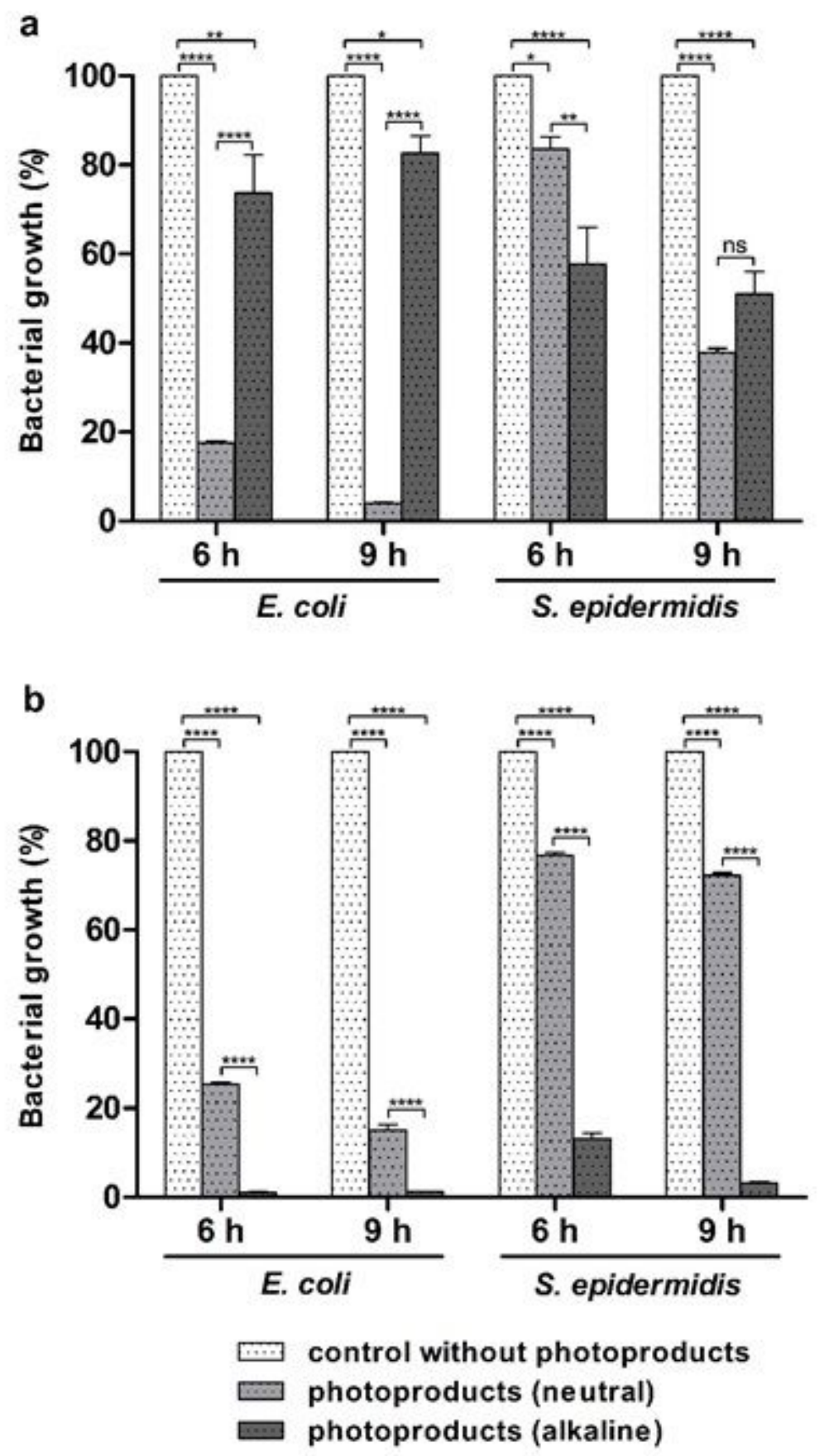

Figure 7

Antibacterial activity of photoproducts of ciprofloxacin (a) and enrofloxacin (b) against E. coli and S. epidermidis after 6 and 9 hours of incubation. Values of $\mathrm{pH}$ : ciprofloxacin neutral $=7.0$; ciprofloxacin alkaline $=8.5$; enrofloxacin neutral $=6.9$; enrofloxacin alkaline $=8.1$. Number of asterisks reflects $p$-value:

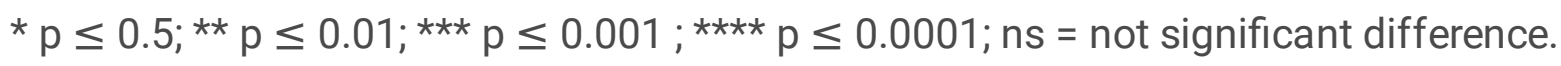

\section{Supplementary Files}


This is a list of supplementary files associated with this preprint. Click to download.

- Tables.pdf 